\title{
C-S (Carbon-Sulfur)
}

\section{H. Okamoto}

The C-S phase diagram was not included in the most recent compilation of phase diagrams [2010Oka].

Figure 1 shows the phase diagram of the $\mathrm{C}$-S system at $1 \mathrm{~atm}$. pressure calculated by [1971Kel] from thermochemical data on various gas species present in the equilibrium state.

\section{References}

1971Kel: H.H. Kellogg, Equilibria in the Systems C-O-S and C-O-S-H as Related to Sulfur Recovery from Sulfur Dioxide, Metall. Trans., 1971, 2, p 2161-2169

2010Oka: H. Okamoto, Desk Handbook: Phase Diagrams for Binary Alloys, 2nd Ed., ASM International, Materials Park, OH, 2010, $855 \mathrm{pp}$

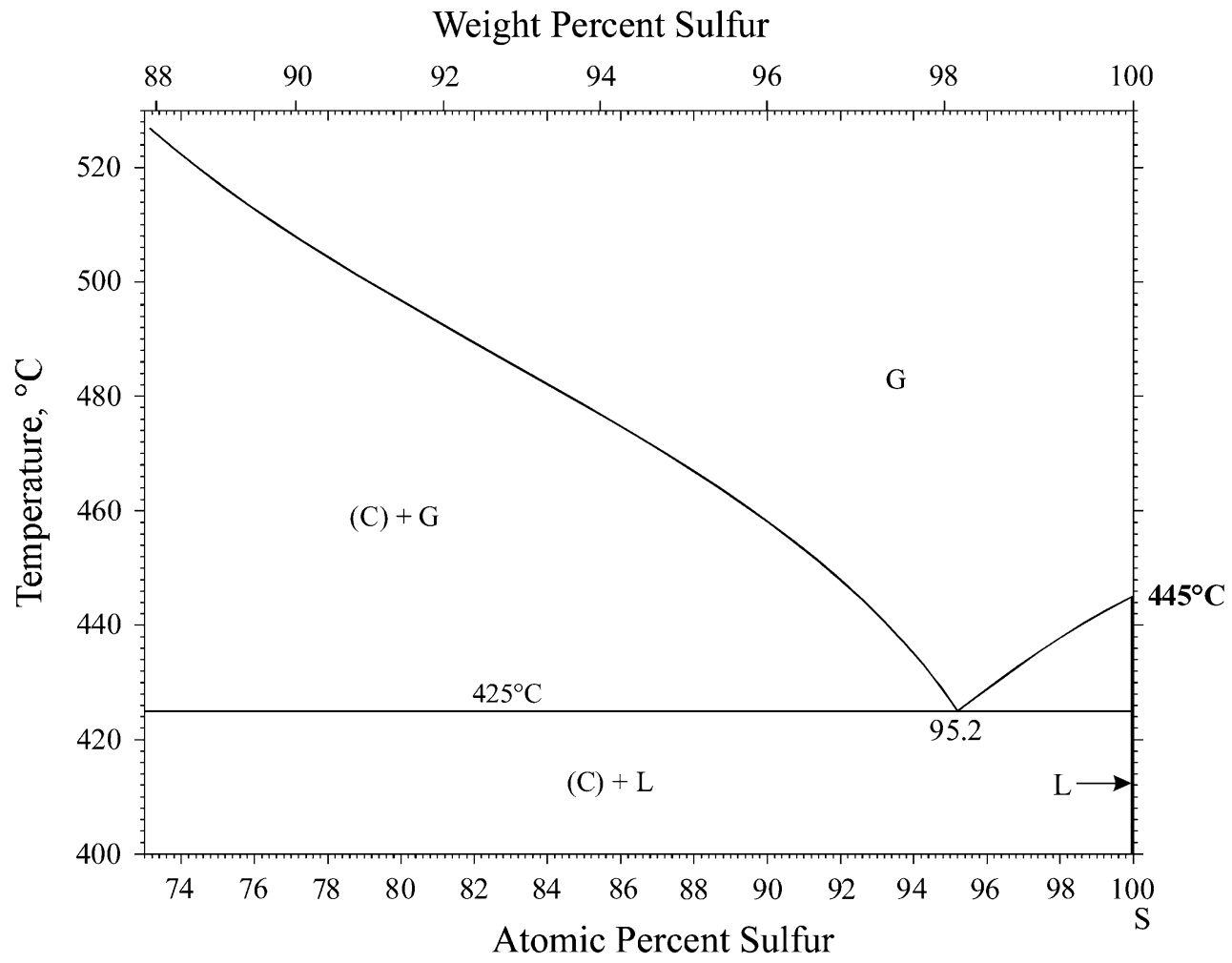

Fig. 1 C-S phase diagram 